\title{
Study on Cooperative Control Strategy of Back-to-Back Dual-PWM Converter based on power Feedforward
}

\author{
Xin DU, Ling ZHU, Chao FU \\ The State Key Laboratory of Alternate Electrical Power System with Renewable Energy Sources \\ North China Electric Power University \\ Bao ding, China \\ E-mail: duxin_ncepu@163.com
}

\begin{abstract}
In traditional back-to-back dual-PWM converter system, DC-bus voltage is affected by load and grid impact of fluctuations, threating the safe operation of the system. In order to reduce the DC voltage fluctuation, a power feedforward control strategy was proposed according to the instantaneous active power balance. In this strategy, the load active power was directly fed-forward to the grid-side given instantaneous active power node through a constructed load state feedforward channel, which avoided the slower process of indirect power adjustment through outer voltage loop. So, the system response speed was greatly accelerated, the DC-bus voltage fluctuation was inhibited effectively, and the dynamic performance of the system had improved. Simulation results demonstrate the effectiveness of the proposed strategy.
\end{abstract}

Keywords-Dual-PWM converter; power feedforward control ; DC-bus voltage

\section{INTRODUCTION}

Back-to-back dual-PWM converter system is constituted by a perfectly symmetrical two voltage source converters connected back to back. DC side of the two converters is connected in parallel. In order to improve the DC voltage of the power quality, filter capacitor is in parallel between the poles of the DC bus [1]. Back-to-back Dual-PWM converter system has many advantages, e.g. flexible control function, adjustable AC side of the power factor and DC voltage controlled. So it accessed to a wide range of applications in HVDC Light, UPFC, flexible power conditioner and other Flexible AC Transmission System [2-7].

When the grid voltage or load state suddenly changes, DC-bus voltage will fluctuate certainly. If not properly controlled, all the energy will store in the capacitor of the DC bus, causing a bus voltage to rise sharply, and then resulting in the power switching devices of the both sides of the DC bus overvoltage breakdown. Therefore, how to suppress the bus voltage fluctuations and improve its dynamic response has been the focus of attention and study.

In this paper, the back-to-back dual-PWM converter is as the research object. Based on dq synchronous rotating coordinate system mathematical model, achieved decoupling control of active and reactive current, and designed a dualloop control of the dual PWM converter and active power feedforward control. The validity of this method is verified by simulation.

\section{Mathematical Model of Three-PHASE Voltage- TYPE PWM RECTIFIER}

\section{A. model of three-phase PWM rectifier}

The back to back dual-PWM converter system is completely symmetrical structure, shown in Fig.1.The main circuit of rectifier side is shown in Figure 2. The inverter side is similar to that. In order to accurately reflect the dynamic characteristics of the controlled object to provide a basis for the design of controlled object controller, mathematical modeling is necessary.

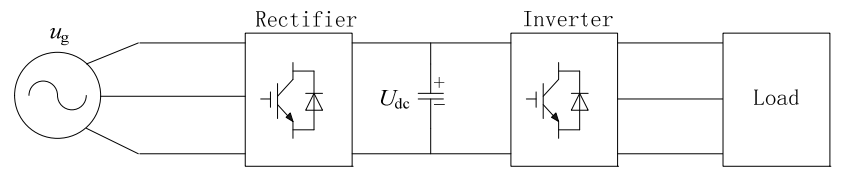

Fig. 1 back to back dual-PWM converter system topology diagram

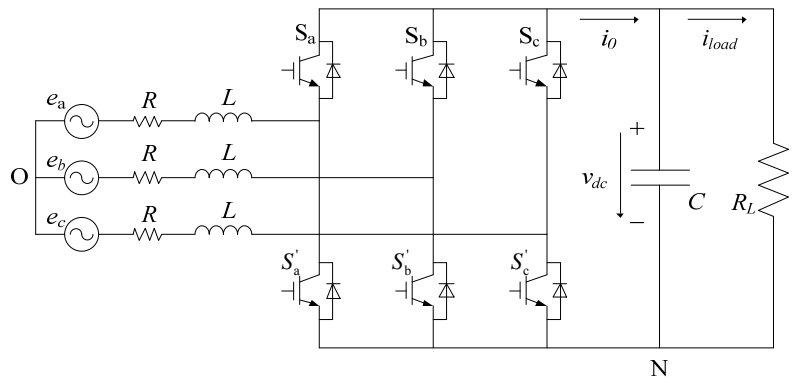

Fig. 2 three-phase PWM rectifier main circuit diagram

$S_{K}=\left\{\begin{array}{l}1 \text { on bridge arm conduction, under off } \\ 0 \text { on bridge arm off, under conduction }\end{array}\right.$

Application of Kirchhoff's voltage law, a three-phase circuit equation is below.

$$
\left\{\begin{array}{l}
L \frac{d i_{a}}{d_{t}}+R i_{a}=e_{a}-\left(v_{d c} S_{a}+v_{N o}\right) \\
L \frac{d i_{b}}{d_{t}}+R i_{b}=e_{b}-\left(v_{d c} S_{b}+v_{N o}\right) \\
L \frac{d i_{c}}{d_{t}}+R i_{c}=e_{c}-\left(v_{d c} S_{c}+v_{N o}\right)
\end{array}\right.
$$

Where, $e_{a}, e_{b}, e_{c}$ represent three-phase equilibrium grid electromotive force. $i_{a}, i_{b}, i_{c}$ represent three - phase current of 
the network side respectively. $v_{d c}$ represents the DC-bus voltage across the capacitor. $v_{N O}$ represents the voltage between the node $\mathrm{N}$ and $\mathrm{O} . L$ is the side of the filter inductor. Assuming that it is linear and it does not consider the saturation. Assuming three-phase system is symmetry, then

$$
\begin{gathered}
e_{a}+e_{b}+e_{c}=0 \\
i_{a}+i_{b}+i_{c}=0
\end{gathered}
$$

Application of Kirchhoff's current law, DC capacitor positive node equations is below.

$$
C \frac{d v_{d c}}{d_{t}}=i_{a} S_{\mathrm{a}}+i_{b} S_{b}+i_{c} S_{c}-i_{\text {load }}
$$

\section{B. dq mathematical model of the two-phase synchronous} rotating coordinate system

In order to analysis the system conveniently, the mathematical model of PWM rectifier in the three - phase symmetrical coordinate system is transformed to dq twophase synchronous rotating coordinate system. The transformation matrix is below.

$$
p=\frac{2}{3}\left[\begin{array}{ccc}
\cos (\omega t) & \cos \left(\omega t-\frac{2 \pi}{3}\right) & \cos \left(\omega t+\frac{2 \pi}{3}\right) \\
-\sin (\omega t) & -\sin \left(\omega t-\frac{2 \pi}{3}\right) & -\sin \left(\omega t+\frac{2 \pi}{3}\right)
\end{array}\right]
$$

Three-phase PWM rectifier model is converted to dq coordinates.

$$
\begin{aligned}
& \left\{\begin{array}{l}
L \frac{d i_{d}}{d_{t}}-\omega L i_{q}+R i_{d}=e_{d}-v_{d c} S_{d} \\
L \frac{d i_{q}}{d_{t}}-\omega L i_{d}+R i_{q}=e_{q}-v_{d c} S_{q}
\end{array}\right. \\
& C \frac{d_{v_{d c}}}{d_{t}}=\frac{3}{2}\left(i_{d} S_{d}+i_{q} S_{q}\right)-\frac{v_{d c}-e_{L}}{R_{L}}
\end{aligned}
$$

Assuming a three-phase grid voltage balance, the threephase grid voltage in the $\mathrm{dq}$ coordinate system is below:

$$
\left[\begin{array}{l}
e_{d} \\
e_{q}
\end{array}\right]=k\left[\begin{array}{l}
e_{a} \\
e_{b} \\
e_{c}
\end{array}\right]=\left[\begin{array}{c}
E \\
0
\end{array}\right]
$$

In $\mathrm{dq}$ coordinate system, basing on the instantaneous power calculation method, the network side of the output of instantaneous active and reactive power is below:

$$
\left\{\begin{array}{c}
P=\frac{3}{2} e_{d} i_{d} \\
Q=-\frac{3}{2} e_{d} i_{q}
\end{array}\right.
$$

\section{C. mathematical model of dq axis decoupling control}

(8) And (9) show that the active current and the reactive current can be controlled, by adjusting the modulation voltage of the $\mathrm{AC}$ side of the rectifier. In order to achieve independent control of the dq-axis component, (11) and (12) is established.

$$
\begin{aligned}
& \left\{\begin{array}{c}
v_{d c} S_{d}=\omega L i_{q}+E-\left(v_{d c} S_{d}\right)^{\prime} \\
v_{d c} S_{q}=-\omega L i_{d}-\left(v_{d c} S_{q}\right)^{\prime}
\end{array}\right. \\
& \left\{\begin{array}{c}
\left(v_{d c} S_{d}\right)^{\prime}=\left(k_{p}+\frac{k_{i}}{s}\right)\left(i_{d}^{*}-i_{d}\right) \\
\left(v_{d c} S_{q}\right)^{\prime}=\left(k_{p}+\frac{k_{i}}{s}\right)\left(i_{q}^{*}-i_{q}\right)
\end{array}\right.
\end{aligned}
$$

So the completely decoupled system is below.

$$
\left\{\begin{array}{l}
L \frac{d i_{d}}{d_{t}}=-R i_{d}+\left(v_{d c} S_{d}\right)^{\prime} \\
L \frac{d i_{q}}{d_{t}}=-R i_{q}+\left(v_{d c} S_{q}\right)^{\prime}
\end{array}\right.
$$

According to (13), active and reactive currents were controlled separately.

\section{D. strategy theoretical analysis of power feedforward control}

In order to reduce the fluctuation of the DC voltage, feedforward load state channel is established, this strategy avoids the relatively slow voltage outer indirectly regulate power, greatly accelerates the response speed of the system to effectively suppress the DC bus voltage fluctuations. Ignoring the power opening of the device turn-off loss, based on the power balance principle, Kirchhoff's current law and Power factor is set to 1 , the below equations are obtained.

$$
\begin{gathered}
C \frac{d v_{d c}}{d_{t}}=i_{0}-i_{\text {load }} \\
3 v i=v_{d c} i_{0} \\
i=k i_{\text {ref }}
\end{gathered}
$$

Where, $i_{0}$ represents output current of rectifier. $i_{\text {load }}$ represents input current of inverter . $v$ and $i$ represent phase to ground voltage and current of load, $v_{d c}$ represents the DCbus voltage, $i_{\text {ref }}$ represents reference value for the inner-loop current. $k$ represents scale factor $(k=1 / \sqrt{2})$. $C$ represents for the DC-bus capacitor .

The equation (14) and (15) show that a part of the active power output of the network side is stored in the DC bus capacitor, a part supplied to the load. The changes of load power feedbackward directly to the inner-loop current can greatly speed up the system response time and reduce the DC voltage fluctuations. The control block diagram is shown in Fig.3. According to (10)-(16), (17) is below.

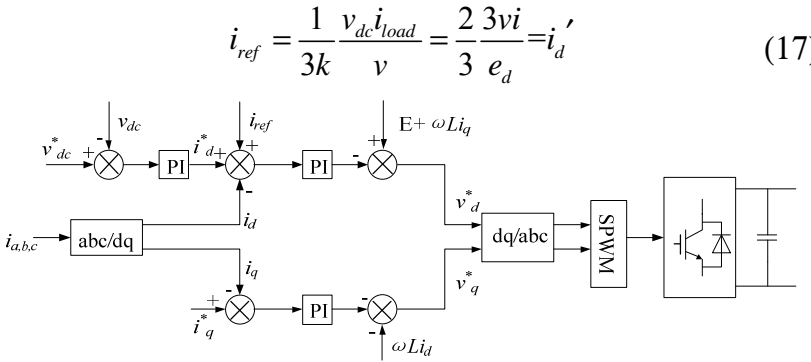

Fig. 3 the power feedforward control block diagram 


\section{Simulation Results}

In order to verify the validity of this feedforward control strategy, Matlab software is used to simulate the back-toback dual-PWM inverter system. Rectifier and inverter use dq synchronous rotating coordinate system of the space vector control strategy. Rectifier use the control of outer-loop voltage and inner-loop current, the inverter uses directly given load voltage control.

Simulation parameters: grid line voltage is $400 \mathrm{~V}$. DCbus voltage is $500 \mathrm{~V}$. AC side inductance is $1.1 \mathrm{mH}$. The DC capacitance is $3310 \mu \mathrm{F}$. The switching frequency is $9 \mathrm{kHz}$. Inverter side per phase load resistance is $10 \Omega$.

The comparison of the DC voltage fluctuation using the power feedforward and no power feedforward control is reacted is Fig. 4. At the $0.2 \mathrm{~s}$, the inverter side is accessed .when no power feedforward, the DC voltage down to $457 \mathrm{~V}$. When using power feedforward, the DC voltage down to about $490 \mathrm{~V}$. Obviously, when using power feedforward, DC voltage fluctuation is very small .At $0.4 \mathrm{~s}$, the load phase-ground voltage changes from $310 \mathrm{v}$ to $60 \mathrm{v}$. When no power feedforward control strategy, the fluctuation of the DC voltage increases about $45 \mathrm{~V}$. When using power feedforward control strategy, the voltage only increases about $10 \mathrm{~V}$. It can be seen, no changing the other parameters, when using power feedforward control, the voltage fluctuation is small. The effects of power feedforward control strategy are obvious.

Fig. 5 shows output A-phase voltage and current waveforms for the inverter side. As can be seen from the figure, at $0.2 \mathrm{~s}$, load side voltage changes from 0 to $310 \mathrm{~V}$. However, at $0.4 \mathrm{~s}$, load side voltage sags from $310 \mathrm{~V}$ to $60 \mathrm{~V}$. The voltage and current can be stabilizing quickly, and the phase of the voltage and current has maintained the same. Power factor has maintained 1.

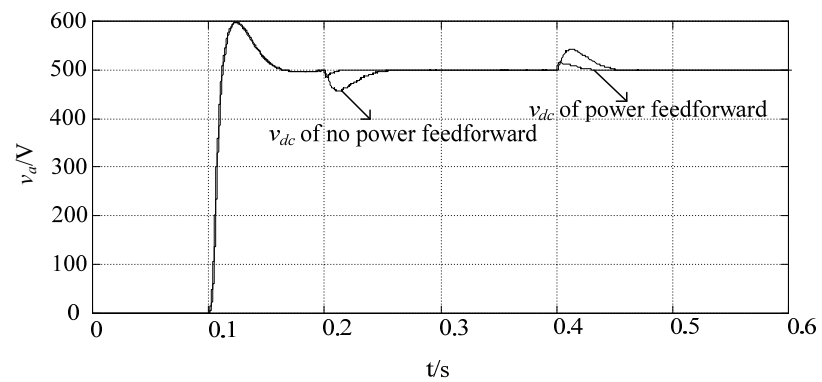

Fig. 4 DC voltage contrast waveform diagram of no power feedforward control and power feedforward control

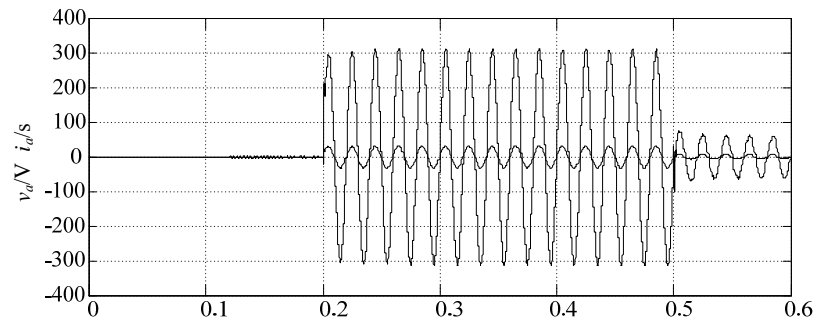

Fig. 5 output A-phase voltage and current waveforms for the inverter side

\section{CONCLUSIONS}

Mathematical model based on voltage -type PWM rectifier in synchronous rotating $\mathrm{dq}$ coordinate system exports mathematical model of power control. Based on Mathematical model of power control, a new strategy of power feedforward control is put forward to solve the problem of active and reactive current coupling. Simulation results show that, when the load voltage sudden changes, the strategy is feasible. This strategy constitutes a back-to-back double PWM converter system. It has the advantages of simple structure, high power factor, greatly speeding up the response speed of the system, the effective suppression of DC-bus voltage fluctuations, improving the dynamic performance of the system.

\section{REFERENCES}

[1] Pena R, Clare J C, Asher G M. A doubly fed induction generator using two back-to-back PWM converters and its application to variable speed wind energy system[J]. IEE Proc., 1996, 143 (3) : 231-241.

[2] Wu R, Dewan S B, Slemon G R. A PWMAC-to-DC converter withfixed switching frequency $[\mathrm{J}]$. IEEE Trans. on Industry Applications, 1990, 2 (5) : 880-885.

[3] Nargari . Performance investigation of a current-controlled voltageregulatedPWM rectifier in rotating and stationary frames[J]. IEEE Trans. on Ind. Electron. 1993, 42 (5) : 396401.

[4] Jong. Fast current controller in three-phase AC/DC boost converter using $\mathrm{d}-\mathrm{q}$ axis crosscoupling $[\mathrm{J}]$. IEEE Trans. on Power Electronics, 1998, 13 (1) : 179-185.

[5] Kim J S. New control scheme for ac-dc-ac converter without dc link electrolytic capacitor[C]. Proc. IEEE PESC'93, Seattle, WA, USA, 1993 : 300-306.

[6] Gu Bon-gwan. A dc link capacitor minimization method through direct capacitor current control[J]. IEEE Trans. on Power Elec., 2002, 33 (5) : 811-817.

[7] NamhoHur. A fast dynamic dc-bus power-balancing scheme for a PWM converter-inverter system[J] . IEEE Trans on IndElec, 2001, 48(4) : 794-803. 